Research Journal of Microbiology 1 (2): 124-135, 2006

ISSN 1816-4935

(C) 2006 Academic Journals Inc., USA

\title{
Effects of Electromagnetic Fields on Structure and Function of Rat Glioma Cell Line
}

\author{
Ah-Ram Sul, Si-Nae Park and Hwal Suh \\ Department of Medical Engineering, Yonsei University College of Medicine, \\ 134 Shinchon-dong, Seodaemun-gu, Seoul 120-752, Korea
}

\begin{abstract}
This study evaluates the effects of electromagnetic fields (EMF) on the rat glioma cell line C6. For periods up to 14 days, cells were exposed to $2 \mathrm{mT}, 60 \mathrm{~Hz}$, sinusoidal EMF for $6 \mathrm{~h}$ per day. We examined whether exposure alters proliferation, differentiation, cell cycle distribution, or actin distribution of the C6. When the initial seeding density was $10^{3}$ cells per $9.6 \mathrm{~cm}^{2}$ growth areas, EMF accelerated the proliferation of $\mathrm{C} 6$. When the initial seeding density was $10^{4}$ cells per $9.6 \mathrm{~cm}^{2}$ growth areas, however, EMF inhibited cell growth. On the other hand, there was no correlation between EMF exposure and cell differentiation. The flow cytometric analysis shows that, when the initial seeding density was $10^{4}$ cells per $9.6 \mathrm{~cm}^{2}$ growth areas, the proliferation potential of EMF-treated cells was higher than that of control cells on 14 days of culture. Regardless of the initial cell seeding, EMF induced the cytoskeletal modification of cells. In conclusion, the observations in this paper support that EMF may modify structure and function of glioma cell.
\end{abstract}

Key words: Glioma, electromagnetic field, proliferation, differentiation, cell cycle, actin, cell lines

\section{Introduction}

Over the past few decades, considerable research has examined the possibility that an extremely low frequency (ELF) electromagnetic field (EMF) might influence biological systems. Unraveling the basics of the interactions between EMF and organisms is a critical issue in biomedicine and cell cultures are used as a delicate model (Pessina et al., 2001). The cellular effects of EMF include changes in proliferation (Schimmelpfeng and Dertinger, 1997; Aldinucci et al., 2000; Wei et al., 2000; Pirozzoli et al., 2003; Chang et al., 2004) and differentiation (Shah et al., 2001; Aaron et al., 2002; Shah et al., 2001; Lohmann et al., 2003; Pirozzoli et al., 2003; Shi et al., 2003; Aaron et al., 2004; Manni et al., 2004), alterations of second-messengers such as $\mathrm{Ca}^{2+}$ (Pessina et al., 2001; Craviso et al., 2002; Zhou et al., 2002) and modifications in shape or morphology (Lee and McLeod, 2000; Golfert et al., 2001; Manni et al., 2002; Manni et al., 2004; Zhang et al., 2005).

The mechanisms underlying the EMF-induced bioeffects are not clearly understood. Hypothetically, the EMF signals affect cell membrane surface by pericellular currents, influencing membrane-receptor complexes or ion-transporting channels. These interactions may trigger transmembrane phenomena and then lead to signal amplification and transduction. The events can alter cytoplasmic concentrations of second messengers such as $\mathrm{Ca}^{2+}$ that modulate macromolecular synthesis

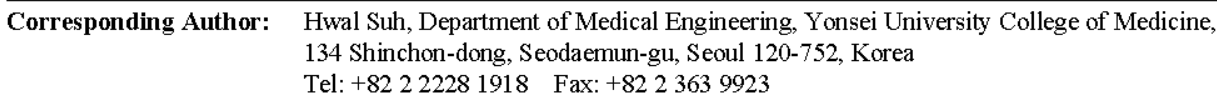


and control cellular growth, differentiation and other functional properties (Tenforde, 1991; Wei et al., 2000; Goodman and Blank, 2002; Zhou et al., 2002; Nie and Henderson, 2003; Aaron et al., 2004).

The researches that focus on the mutagenic (carcinogenic) effect of EMFs have also been widely conducted. Nevertheless, no obvious relationships have been proven until now. Epidemiological verification implying that EMF exposure may cause cancer is inadequate; even so, the feasibility that exposure possesses a deleterious aspect has still not been rejected (Bodega et al., 2005).

Although there is an agreement that EMF acts on certain cellular behaviors, the results have been largely inconsistent. Extrapolation or replications among different studies are complicated because the experimental approach concerning effects of EMF on cells is characterized by a number of nonlinearities (window effects with respect to frequency, amplitude and time of exposure) and peculiarities (cell type, age and treatment) (Manni et al., 2002; Manni et al., 2004; Tokalov and Gutzeit, 2004).

There are numerous publications on the effects of ELF EMF on neuronal cells in vitro, while the results are indefinite and inconclusive so far (Pessina et al., 2001; Shah et al., 2001; Craviso et al., 2002; Pirozzoli et al., 2003; Bodega et al., 2005). Astrocytes are one of the most abundant neuronal cell types. They regulate essential functions such as neuronal migration, neurite outgrowth, osmotic homeostasis, maintenance of the blood-brain barrier and synaptogenesis (Pessina et al., 2001). To determine the effects of EMF on neuronal cells, we selected the rat C6 glioma that is a commonly used example for studying astrocytes. Astrocytes constitute a heterogeneous population of glial cells. The C6 is a fast-growing cell line possessing an undifferentiated phenotype and oligodendrocytic, astrocytic and neuronal properties. Early passage of C6 represents features of oligodendorocytic and astrocytic progenitors. The agent dibutyryl cyclic adenosine monophosphate (cAMP) is known to switch the C6 cell phenotype from bipotential neuroglial precursor to a more mature type II astrocyte by elevating intracellular concentrations of cAMP (Anciaux et al., 1997; Roymans et al., 2001). Additionally, consisting of microtubules and microfilaments (actin filaments), astrocytes have a well-grown intermediate filament system. It has been proposed that actin filament is a cellular interaction site for EMFs. Glial fibrillary acidic protein (GFAP) is the main component of the actin filaments in mature astrocytes, hence it can be chosen as a reliable marker for astroglial cells (Bodega et al., 2005).

Since no information is apparently available on the interaction of EMF with astrocytoma cells, the specific purpose of this study was to elucidate the effects of $2 \mathrm{mT}, 60 \mathrm{~Hz}$, sinusoidal EMF on the proliferation, differentiation, cell cycle distribution and actin distribution of the $\mathrm{C} 6$ cells.

\section{Materials and Methods}

\section{Reagents and Antibodies}

All reagents used were standard high-quality chemicals from either GIBCO (New York, USA) or Sigma (Saint Louis, USA) unless otherwise stated. Antibodies were purchased from either Santa Cruz Biotechnology (Santa Cruz, USA) or Amersham Biosciences (Buckinghamshire, England).

\section{Cell Culture}

The C6 line of rat glioma cells was obtained from the Korean Cell Line Bank (KCLB, Seoul, Korea). The C6 cells were grown in Ham's F-10 nutrient mixture supplemented with 15\% horse serum, $2.5 \%$ fetal bovine serum (FBS) and $1 \%$ antibiotic-antimycotic solution. 


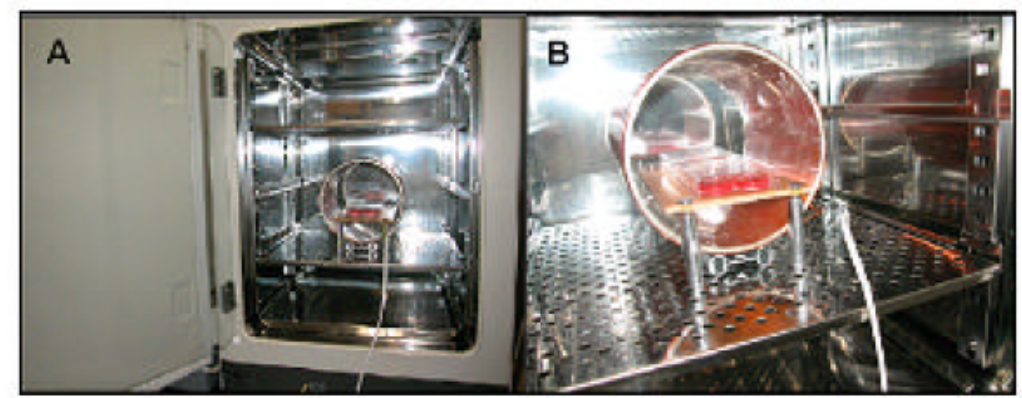

Fig. 1: EMF exposure system. (A) Placement of the system in a cell culture incubator. (B) Magnified view of the experimental setup

\section{EMF Exposure System and Conditions}

As shown in Fig. 1, EMFs were generated by a self-designed solenoid (C.U.TECH, Guri, Korea). The coil was built by winding 720 turns of $1 \mathrm{~mm}$ diameter copper wire to form a cylindrical solenoid (radius: $10.3 \mathrm{~cm}$, length: $24 \mathrm{~cm}$ ) (Fig. 1). The apparatus was able to generate a $60 \mathrm{~Hz}$, sinusoidal EMF with a variable magnetic flux density not exceeding $4 \mathrm{mT}$. After ethylene oxide (EO) gas sterilization, the system was placed in a cell culture incubator (MCO-15AC, Sanyo, Osaka, Japan) with $5 \% \mathrm{CO}_{2}$. Throughout the entire experiment, the temperature into the solenoid measured at the sample level was kept at $37 \pm 0.2^{\circ} \mathrm{C}$.

\section{Experimental Protocol}

Cells were seeded at a density of $10^{3}$ or $10^{4}$ cells per $9.6 \mathrm{~cm}^{2}$ growth areas in a 6-well plate and the plate was maintained for $4 \mathrm{~h}$ in order to promote cell attachment. The cells were randomly divided into control and EMF-treated groups. The control group was grown in a separate incubator without an exposure system. The experimental groups were exposed to $2 \mathrm{mT}$ EMF for $6 \mathrm{~h}$ a day. Temperature, humidity and $\mathrm{CO}_{2}$ were measured and adjusted to be identical for both control and experimental groups. The cells were cultured for a period up to 14 days.

\section{Proliferation Assay}

The proliferative responses of cells were evaluated by a colorimetric assay (Landegren, 1984). Cell numbers at 0 day indicate the number of cells $4 \mathrm{~h}$ after initial cell seeding. At $1,3,5,7,10$ and 14 days after incubation, cell proliferation from the control and EMF-treated groups was quantified by hexosaminidase assay. Briefly, the cells were washed thoroughly with Phosphate-buffered Saline (PBS) and soaked in $100 \mu \mathrm{L}$ of hexosaminidase substrate $(3.75 \mathrm{M} \rho$-nitrophenyl-N-acetyl- $\alpha$-Dglucosaminide, $0.25 \%$ Triton X-100, $0.05 \mathrm{M}$ citrate buffer, $\mathrm{pH} 5.0$ ) in each well of a 6-well plate. After a $1 \mathrm{~h}$ incubation in a humidified atmosphere containing $5 \% \mathrm{CO}_{2}$ at $37^{\circ} \mathrm{C}, 75 \mu \mathrm{L}$ of stop/development buffer ( $5 \mathrm{mM}$ EDTA, $50 \mathrm{mM}$ glycine, $\mathrm{pH} 10.4$ ) was added to each well. Optical density was measured at $405 \mathrm{~mm}$. Absorbencies were converted into absolute cell numbers based on an established standard curve.

\section{Differentiation Assay}

In order to assess the differentiation of C6 cells, the expression of GFAP was detected by conventional western blotting (Roymans et al., 2001; Nie and Henderson, 2003; Pirozzoli et al., 2003; 
Zeng et al., 2003; Tokalov and Gutzeit, 2004; Bodega et al., 2005). The expression of glyceraldehyde3-phosphate dehydrogenase (GAPDH), the house-keeping enzyme, remained unchanged under the experimental conditions and was used to monitor the equivalence of protein loading.

Every other day, the cell culture medium was renewed with either the medium containing $1 \mathrm{mM} \mathrm{N} \mathrm{N}^{6}-\mathrm{O}^{\prime 2}$-dibutyryl adenosine 3',5'-cyclic monophosphate (dbcAMP) or normal medium (Anciaux et al., 1997; Roymans et al., 2001). The samples were homogenized in a Radio Immunoprecipitation Assay (RIPA) lysis buffer (50 mM Tris- $\mathrm{HCl} \mathrm{pH} 7.5,0.15 \mathrm{M} \mathrm{NaCl}, 2 \mathrm{mM}$ EDTA, $1 \%$ deoxycholic acid, $1 \%$ NP-40 with protease inhibitors), then centrifuged at $4^{\circ} \mathrm{C}, 12,000 \mathrm{rpm}$ for $10 \mathrm{~min}$. Proteins were extracted from the soup and quantified using a Bradford assay. Bovine serum albumin (BSA) was used as the standard for the protein assay. Then, equal amount of protein from each extract was added to a $10 \%$ sodium dodecyl sulfate-polyacrylamide gel and electrophoretically transferred to PVDF membranes (Amersham Phamacia Biotech, Buckinghamshire, England). After blocking in freshly prepared blotting buffer containing 5\% skim milk (DIFCO Laboratories, Detroit, USA) and $0.1 \%$ Tween 20 (Hayashi Pure Chemical Industries Ltd., Osaka, Japan) for $1 \mathrm{~h}$ at room temperature with constant agitation, the membranes were incubated with anti-GFAP from rabbit or anti-GAPDH from goat as a standard for $1 \mathrm{~h}$ at room temperature. After three PBS-T (PBS containing $1 \%$ skim milk and $0.1 \%$ Tween 20 ) washes, the membranes were incubated with anti-rabbit or anti-goat IgG, HRP-linked antibody for $1 \mathrm{~h}$ at room temperature. The membranes were washed again three times with PBS-T and the signals were visualized using an ECL Plus western blotting detection system (Amersham Biosciences, Buckinghamshire, England). Images were captured using Image Reader LAS100 Lite software, Version 1.1 (FUJIFILM, Tokyo, Japan). Densitometric analyses were performed with TINA software, Version 2.10e (Catholic University Medical College, Seoul, Korea).

\section{Cell Cycle Analysis}

Cell cycle was measured by means of flow cytometry (Schimmelpfeng and Dertinger, 1997; Mangiacasale et al., 2001; Tokalov and Gutzeit, 2004). The analyses were performed 10 or 14 days after cell plating. In each sample, $2 \times 10^{6}$ cells were washed in PBS and fixed in absolute ethyl alcohol at $4^{\circ} \mathrm{C}$ for at least $1 \mathrm{~h}$. For DNA quantification, cells were washed in PBS again and incubated at $4^{\circ} \mathrm{C}$ for $3 \mathrm{~h}$ with $1 \mathrm{~mL}$ propidium iodide (PI) staining solution $\left(50 \mu \mathrm{g} \mathrm{mL}^{-1} \mathrm{PI}\right.$ in PBS) and $50 \mu \mathrm{L}$ of Ribonuclease (RNase) A stock solution $\left(10 \mu \mathrm{g} \mathrm{mL}^{-1}\right.$ RNase A). DNA content was assessed by flow cytometry using FACSCalibur (Becton Dickinson, New Jersey, USA). The percentage of cells in each phase of the cell cycle was analyzed with ModiFit software (Becton Dickinson, New Jersey, USA).

\section{Fluorescence Microscopy Analysis}

Fluorescence microscopy analysis was carried out using a slightly modified procedure of previously reported techniques (Manni et al., 2002; Manni et al., 2004). Cells on cover glasses were washed with PBS and fixed in $4.0 \%$ paraformaldehyde for $10 \mathrm{~min}$ at room temperature. Then, cells were washed again with PBS and permeabilized for 10 min with $0.1 \%$ Triton X-100. After washing again, the cells were stained with fluorescein isothiocyanate (FITC) labeled phalloidin $\left(0.2 \mathrm{mg} \mathrm{mL}^{-1}\right.$ ) in blocking solution $(1 \%(\mathrm{w} / \mathrm{v})$ bovine serum albumin (BSA)/PBS, $1 \mathrm{~mL}$ ) overnight in a dark room at room temperature. The next day, the cells were thoroughly washed several times with PBS to remove unbound phalloidin conjugate and mounted with a $90 \%$ glycerol solution. Actin distribution was monitored using an Image Analyzer (Olympus, Tokyo, Japan) and a MetaMorph imaging system (Universal Imaging Corporation, West Chester, USA). 


\section{Statistical Analysis}

Statistical analysis was performed with SPSS 10.0.1 package (SPSS Inc., Chicago, USA). The results were calculated from six independent experiments. The data are given as the mean \pm Standard Deviation (SD) of four different sets of experiments $(n=6-2)$. Proliferation and cell cycle distribution data were analyzed for statistical significance by t-test to determine the difference between control and EMF-treated cells. Differentiation data was evaluated for statistical significance using one-way analysis of variance (ANOVA) followed by Bonferroni test for specific between-group differences. Differences were considered to be statistically significant when ${ }^{*} \mathrm{p}<0.05$ and highly statistically significant when $* * \mathrm{p}<0.005$.

\section{Results}

\section{Effects of EMF on Cell Proliferation}

After the EMF exposure, almost all cells ( $>98 \%$ ) were viable as assayed by the trypan-blue dye exclusion technique (data not shown). Figure 2 show growth curves obtained for a quantitative evaluation of the effect of $2 \mathrm{mT}, 60 \mathrm{~Hz}$, sinusoidal EMF on C6 cells. It shows the trend of cell numbers up to 14 days after seeding for the control and EMF-treated groups. Cell numbers at day 0 were calculated $4 \mathrm{~h}$ after initial cell seeding in order to examine how many cells adhered to the plate. There was no difference in initial cell numbers between the control and treatment groups.

When the initial seeding concentration was $10^{3}$ cells per $9.6 \mathrm{~cm}^{2}$ growth areas (Fig. 2A), cells grew slowly for 5 days after plating due to insufficient cell-to-cell contact. The cells revealed a dramatic growth increase from day 5 after culture and reached maximum number at day 10. After day 10, cell numbers decreased. The growth of EMF-treated cells was more than that of control cells on day 10 and 14 of incubation.

When the initial seeding concentration was $10^{4}$ cells per $9.6 \mathrm{~cm}^{2}$ growth areas (Fig. 2B), the number of cells continuously increased during the entire experimental period. Cells were rapidly growing from day 3 to 7 . After 7 days of culture, the proliferation rate reduced. The growth of EMF-treated cells was less than that of control cells after day 7,10 and 14 of incubation.

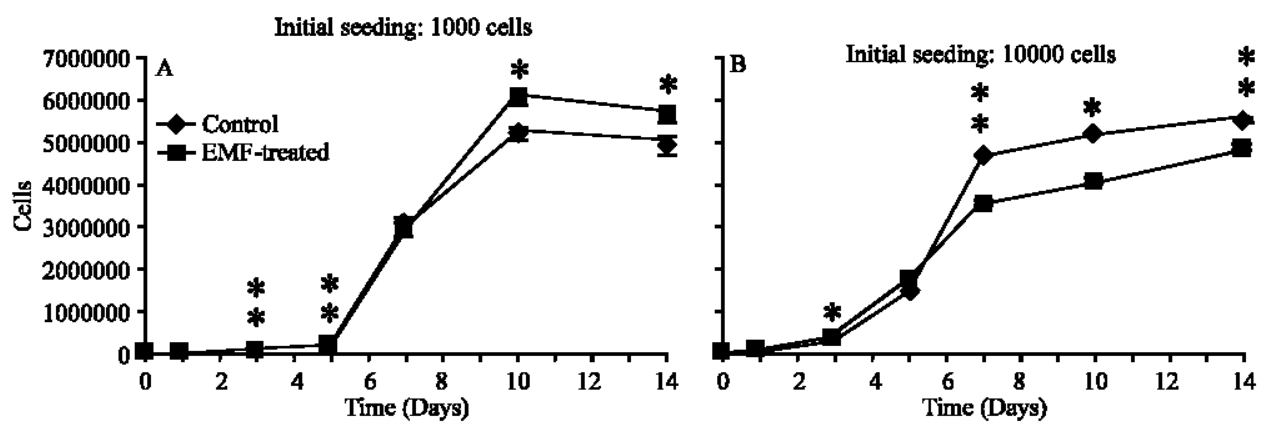

Fig. 2: Effect of $2 \mathrm{mT}, 60 \mathrm{~Hz}$, sinusoidal EMF on proliferation of C6 cells. Growth curves for control and EMF-treated cells are shown. Initial seeding concentration was $10^{3}(\mathrm{~A})$ or $10^{4}(\mathrm{~B})$ cells per $9.6 \mathrm{~cm}^{2}$ growth areas. EMF was applied to the cells $6 \mathrm{~h}$ per day for 14 days. Points represent the mean $\pm \mathrm{SD}$ of four different sets of experiments $(n=6-2)$. Statistical analysis was performed by t-test (Control vs. EMF-treated; ${ }^{*} \mathrm{p}<0.05,{ }^{* *} \mathrm{p}<0.005$ ) 


\section{Effects of EMF on Cell Differentiation}

The morphology of $\mathrm{C} 6$ cells grown in unsupplemented control medium is shown in Fig. $3 \mathrm{~A}$ and $\mathrm{C}$. The cells are spongioblastic with a roughly bipolar appearance and their nuclei are relatively small with distinct margins. The appearance of $C 6$ cells cultured in medium containing $1 \mathrm{mM}$ dbe AMP for 1 day is shown in Fig. 3B and D. The cells changed their shape from a bipolar to a stellate form. The morphological change was started as early as $4 \mathrm{~h}$ after the initiation of treatment and most of the cells developed long, thin, multipolar cytoplasmic processes within $24 \mathrm{~h}$ after addition of $1 \mathrm{mM}$ dbc AMP. It has been proposed that the morphological changes relating to differentiation are from actin depolymerization, actin rearrangement and a redistribution of intermediate filaments (Anciaux et al., 1997). These cAMP-dependent shape changes of $\mathrm{C} 6$ cells were sustained during the entire experimental period. $\mathrm{C} 6$ cells were cultured with (Fig. 3C and D) or without (Fig. 3A and B) a $2 \mathrm{mT}, 60 \mathrm{~Hz}$, sinusoidal EMF. On the contrary, the morphological responses of cells measured after EMF exposures were negligible.

GFAP is a $50 \mathrm{kDa}$ type III intermediate filament protein chiefly found in cells of astroglial lineage. Since GFAP synthesis is elevated by cAMP-mediated induction of glial progenitor cells toward a more astrocytic form, it has been employed as a trustworthy differentiation marker for normal astrocytes and tumors of astrocytic origin (Anciaux et al., 1997; Roymans et al., 2001). The western (Fig. 4A) is representative of four independent experiments. The amounts of GFAP and GAPDH expressed were quantified by densitometric analysis. Cells were initially seeded as $10^{3}$ (Fig. $4 \mathrm{~B}$ ) or $10^{4}$ (Fig. 4C) cells per $9.6 \mathrm{~cm}^{2}$ growth areas. The samples were prepared 14 days after plating. Resulting values were denoted by GFAP/GAPDH ratio, which is calculated by division of the GFAP expression
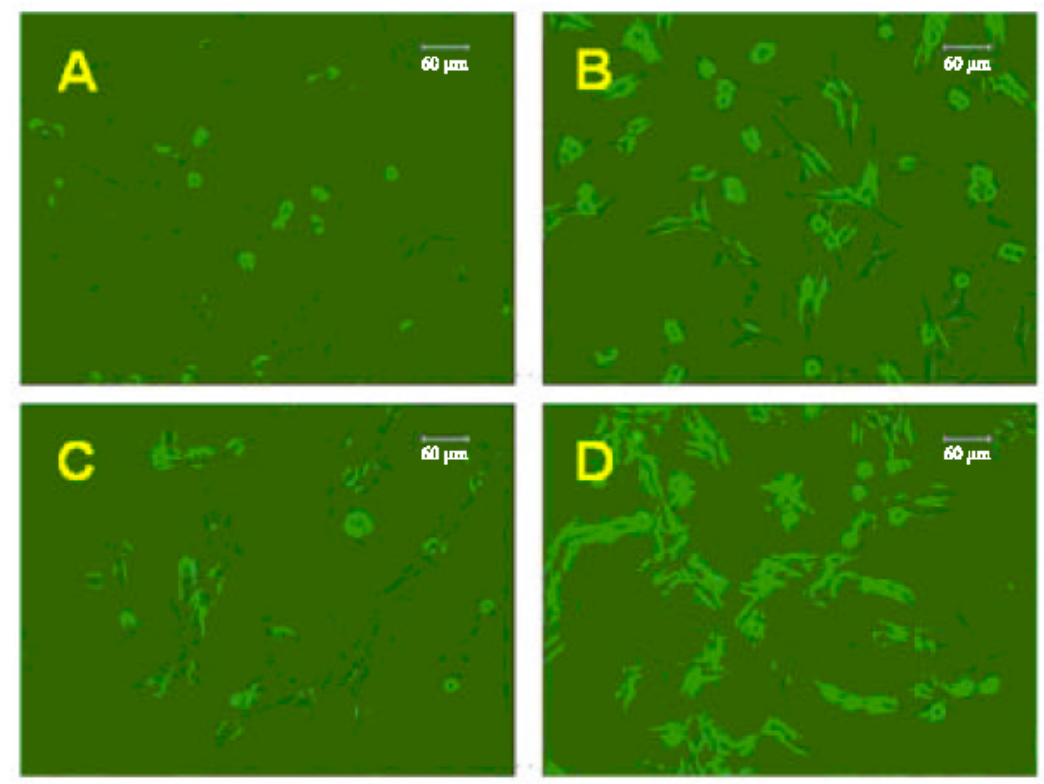

Fig. 3: The morphology of $C 6$ cells grown in unsupplemented control medium $(A, C)$ or $1 \mathrm{mM}$ dbcAMP-treated medium (B, D) for 1 day. C6 cells were cultured with $(C, D)$ or without $(A$, B) $2 \mathrm{mT}, 60 \mathrm{~Hz}$, sinusoidal EMF. Initial seeding concentration was $10^{4}$ cells per $9.6 \mathrm{~cm}^{2}$ growth areas. Scale bar, $60 \mu \mathrm{m}$ 


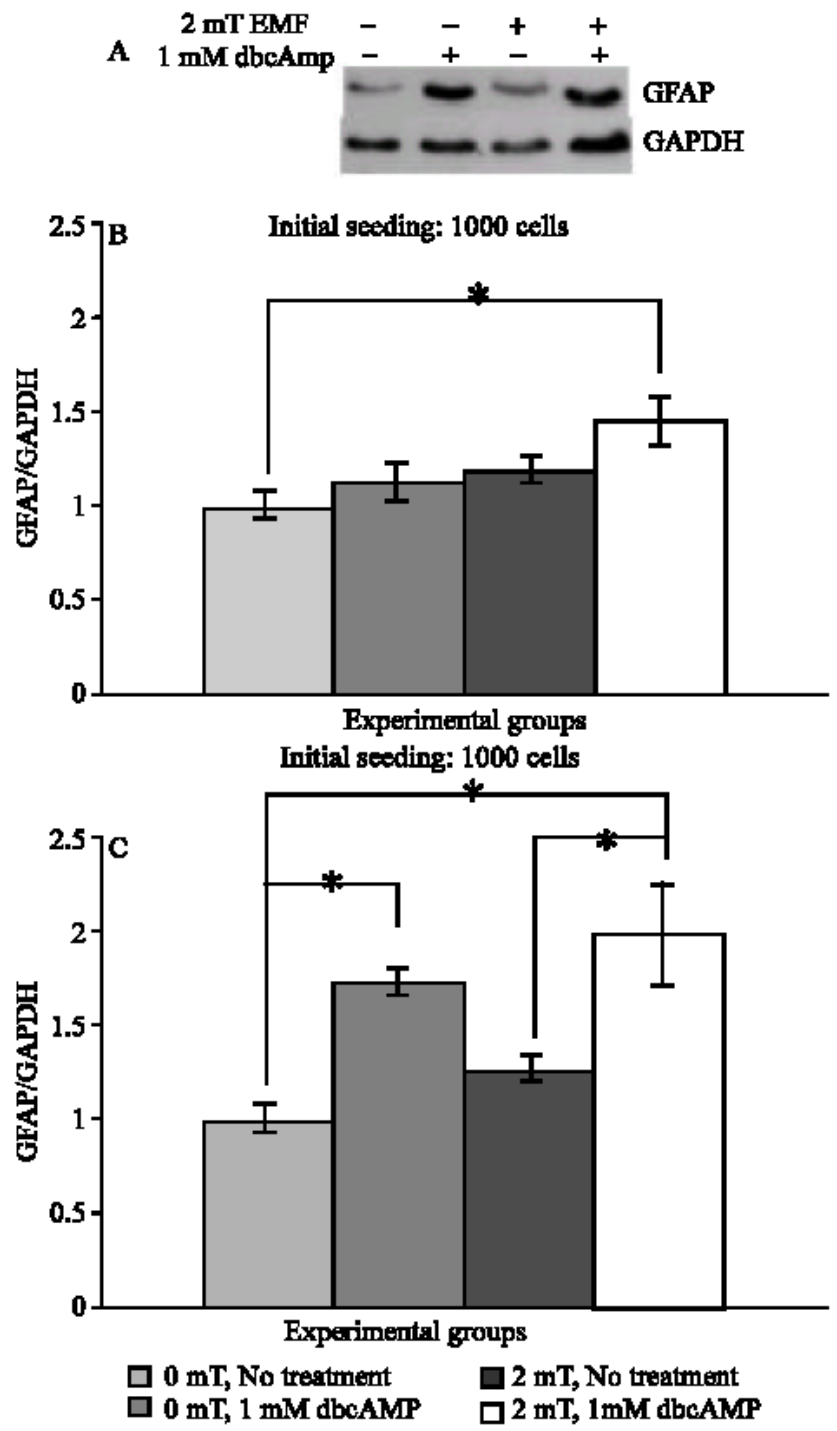

Fig. 4: Effect of $2 \mathrm{mT}, 60 \mathrm{~Hz}$, sinusoidal EMF on differentiation of $\mathrm{C} 6$ cells. Western blot analysis was carried out with anti-GFAP and anti-GAPDH. The representative blot is presented in (A). The samples were prepared 14 days after plating. The GFAP/GAPDH ratio of the no treatment group, $0 \mathrm{mT}$, was normalized to 1 . The bars represent the mean $\pm \mathrm{SD}$ of four different sets of experiments $(n=6-2)$. One-way ANOVA showed statistically significant differences for all the results. Post-hoc Bonferroni test was performed to compare all groups of subjects each other $\left({ }^{*} \mathrm{p}<0.05\right)$ 
Res. J. Microbiol., 1 (2): 124-135, 2006

\begin{tabular}{|c|c|c|c|c|c|c|c|c|c|c|c|c|}
\hline & \multicolumn{12}{|c|}{ Cell cycle distribution (\%) } \\
\hline & \multicolumn{6}{|c|}{ Initial seeding: 1000 cells } & \multicolumn{6}{|c|}{ Initial seeding: 10000 cells } \\
\hline & \multicolumn{3}{|l|}{10 Day } & \multicolumn{3}{|l|}{14 Day } & \multicolumn{3}{|l|}{10 Day } & \multicolumn{3}{|l|}{14 Day } \\
\hline & G0-G1 & $\mathrm{S}$ & $\mathrm{G} 2-\mathrm{M}$ & G0-G1 & $\mathrm{S}$ & $\mathrm{G} 2-\mathrm{M}$ & $\mathrm{G} 0-\mathrm{G} 1$ & $\mathrm{~S}$ & $\mathrm{G} 2-\mathrm{M}$ & $\mathrm{G} 0-\mathrm{G} 1$ & $\mathrm{~S}$ & $\mathrm{G} 2-\mathrm{M}$ \\
\hline Control & $\begin{array}{l}85.8 \\
\pm 0.6\end{array}$ & $\begin{array}{l}8.4 \\
\pm 1.0\end{array}$ & $\begin{array}{l}5.8 \\
\pm 0.8\end{array}$ & $\begin{array}{l}87.1 \\
\pm 0.9\end{array}$ & $\begin{array}{l}6.5 \\
\pm 0.7\end{array}$ & $\begin{array}{l}6.5 \\
\pm 0.7\end{array}$ & $\begin{array}{l}86.0 \\
\pm 2.7\end{array}$ & $\begin{array}{r}10.4 \\
\pm 3.4\end{array}$ & $\begin{array}{l}3.6 \\
\pm 1.4\end{array}$ & $\begin{array}{l}84.9 \\
\pm 0.4\end{array}$ & $\begin{array}{l}6.2 \\
\pm 0.6\end{array}$ & $\begin{array}{l}9.0 \\
\pm 0.5\end{array}$ \\
\hline $\begin{array}{l}\text { EMF- } \\
\text { treated }\end{array}$ & $\begin{array}{l}74.2 \\
\pm 4.9\end{array}$ & $\begin{array}{l}17.8 \\
\pm 4.2\end{array}$ & $\begin{array}{l}8.0 \\
\pm 2.5\end{array}$ & $\begin{array}{l}85.4 \\
\pm 1.2\end{array}$ & $\begin{array}{l}7.0 \\
\pm 0.7\end{array}$ & $\begin{array}{l}7.6 \\
\pm 1.7\end{array}$ & $\begin{array}{l}92.7 \\
\pm 3.0\end{array}$ & $\begin{array}{l}5.3 \\
\pm 2.1\end{array}$ & $\begin{array}{l}2.0 \\
\pm 1.1\end{array}$ & $\begin{array}{l}84.1 \\
\pm 0.3\end{array}$ & $\begin{array}{l}8.5 \\
\pm 0.7^{*}\end{array}$ & $\begin{array}{l}7.5 \\
\pm 0.5^{*}\end{array}$ \\
\hline
\end{tabular}

Data given as the mean \pm SD of four different sets of experiments $(n=6-2)$. Statistical analysis was performed by t-test (Control vs. EMF-treated; * $\mathrm{p}<0.05$ )
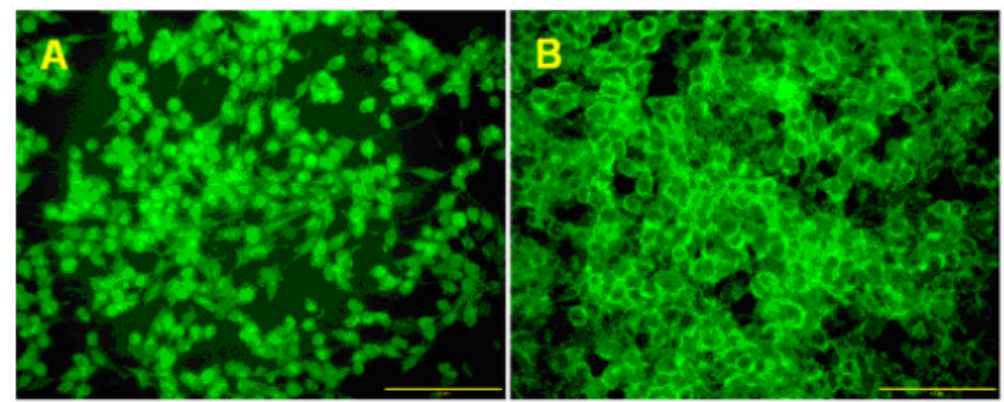

Fig. 5: Fluorescence microscopy analysis. (A) Actin distribution, as detected by phalloidin fluores cence in control C6 cells. (B) Effect to $2 \mathrm{mT}, 60 \mathrm{~Hz}$, sinusoidal EMF on phalloidinlabelled actin. Analyses were performed 10 days after culture. Images were obtained with $40 \mathrm{x}$ objectives. Scale bar, $50 \mu \mathrm{m}$

by the GAPDH expression. The GFAP/GAPDH ratio of the no treatment group, $0 \mathrm{mT}$ was nomalized to 1 . One-way ANOVA showed statistically significant differences for all the results. Posthoc Bonferroni test was performed to compare all groups of subjects each other $\left({ }^{*} \mathrm{p}^{<0.05}\right)$. When the initial seeding concentration was $10^{4}$ cells per $9.6 \mathrm{~cm}^{2}$ growth areas (Fig. $4 \mathrm{~B}$ ), the expression of GFAP in $\mathrm{C} 6$ cells became upregulated by the stimulation of cells with $1 \mathrm{mM}$ dbcAMP. However, we failed to observe any remarkable difference in GFAP synthesis between control and EMF-treated groups.

\section{Effects of EMF on Cell Cycle Distribution}

The hexosaminidase assay, though helpful to estimate cell numbers, does not give information on the progression of the cell cycle and actual cell duplication. Therefore, the effect of EMF exposure on the proliferation of $\mathrm{C} 6$ cells was also confirmed by flow cytometry using the PI staining method.

The cell cycle distributions of control and EMF-treated C6 cells (Table 1). Percentages (\%) of cells in $\mathrm{G} 0-\mathrm{G} 1, \mathrm{~S}$ and $\mathrm{G} 2-\mathrm{M}$ phases are calculated. The majority of cells were arrested in $\mathrm{G} 0-\mathrm{G} 1$ stages of the cell cycle and the remaining cells were arrested in G2-M stages.

When the initial seeding concentration was $10^{3}$ cells per $9.6 \mathrm{~cm}^{2}$ growth areas, the number of G0-G1 phase cells after 14 days of culture increased compared to that of 10 days of incubation. This finding was paralleled by a corresponding decline in the proportion of $S$ phase cells. The enrichment of cells in the G0-G1 phase implies a decrease in the growth potential of the cultures, presumably 
caused by accumulation of cell metabolites and medium spoilage, which is usually followed by cell apoptosis or necrosis (Mangiacasale et al., 2001).

When the initial seeding concentration was $10^{4}$ cells per $9.6 \mathrm{~cm}^{2}$ growth areas, the fraction of EMF-treated cells in S phase increased after 14 days of incubation. This result is interpreted to reflect that the proliferating ability of EMF-treated cells enhanced. Besides, on 14 days of culture, the percentage of EMF-treated cells in S phase was higher than that of control cells. This means that EMF promoted cell proliferation under that circumstance.

\section{Effects of EMF on Actin Distribution}

The distribution of actin filaments was detected by phalloidin fluorescence through the whole volume in C6 cells. Results from control (Fig. 5B) and EMF-treated (Fig. 5B) cells are shown. Initial seeding concentration was $10^{4}$ cells per $9.6 \mathrm{~cm}^{2}$ growth areas. Analyses were performed 10 days after culture. Fluorescence microscopy analysis of control cells demonstrated that intracellular distribution of actin filaments was homogenous. After $60 \mathrm{~h}$ of exposure to EMF, actin appeared predominantly segregated around the cell membrane. Furthermore, exposure to EMF altered the morphology of the cells. EMF-exposed cells were larger than control cells.

\section{Discussion}

Cells react to changes in the environment. The stimuli include physical stresses, increased concentrations of signaling molecules and EMFs. However, the cells respond slightly to the EMFs because the fields perturb homeostasis only a small degree. EMFs can modify structure and function of the cells, but they do not deliver large amount of energy to the cells (Pessina et al., 2001).

In spite of many reports on the cellular effects of EMF, most studies demonstrate conflicting results. For instance, a set of researches have investigated the effects of EMF on cell proliferation and some of them indicate that EMF had a positive effect in promoting cell growth (Wei et al., 2000; Aaron et al., 2004; Chang et al., 2004). On the other hand, some investigators noted zero effects (Schimmelpfeng and Dertinger, 1997). These discrepancies are explained by the intensity and frequency window effect. Moreover, physiological responses to EMF are species-and cell-dependent. The factors which are potential modifiers of the biological responses toward the fields are: 1) different field types, e.g., EMFs with varying waveforms, frequencies and intensities; 2) different cell types (transformed or primary cells) are exposed as single cell suspensions, monolayers, or spheroids and under various physiological conditions (degree of differentiation or activation). Due to the broad variations in exposure conditions, multiplicity of sources and adopted protocols, it is difficult to make any direct comparisons among separately conducted studies (Schimmelpfeng and Dertinger, 1997; Wei et al., 2000; Mangiacasale et al., 2001; Shah et al., 2001; Manni et al., 2002; Pirozzoli et al., 2003; Manni et al., 2004; Tokalov and Gutzeit, 2004; Bodega et al., 2005).

The nervous system is highly sensitive to EMF and gliomas are considered as the major cells associated with neural reactions to EMF (Bodega et al., 2005). Thus, the C6 glioma cell line provides an excellent model to study the effects of EMF on astrocytes (Anciaux et al., 1997; Roymans et al., 2001). Results from experiments using tumor cells must be understood carefully, but we employed C6 cells because it has been discovered that results from astrocytoma cell lines are analogous to those from primary astrocytes (Pessina et al., 2001). Astroglial physiology is typically revealed in expression, content and/or the degree of GFAP polymerization (Bodega et al., 2005). 
No researcher solved the plausible biophysical mechanism to account for the involvement between cellular effect and exposure to EMF yet. According to recent publications, protein kinase C (PKC) plays a central role in the proliferation of glioma cells. It was inferred that the most responsible signal transduction for proliferation of glioma cells in vitro is through a PKC-mediated pathway. Some studies mentioned that EMF exposure upregulated PKC activity (Wei et al., 2000).

The first application of EMFs for clinical aims as noninvasive therapeutic agent was the use of pulsed EMFs to facilitate bone fracture repair. A number of literatures on the enhancement of bone cell growth and bone healing by pulsed EMF have been published. Pulsed and sinusoidal EMF produces fundamentally different effects, but the papers involving bone regeneration using sinusoidal EMF present similar data compared to pulsed EMF (Wei et al., 2000; Guerkov et al., 2001; Manni et al., 2002; Lohmann et al., 2003; Aaron et al., 2004; Chang et al., 2004; Manni et al., 2004).

Many authors have investigated the influence of EMFs in the mT range of magnetic flux density on cells (Schimmelpfeng and Dertinger, 1997; Aldinucci et al., 2000; Lee and McLeod, 2000; Golfert et al., 2001; Pessina et al., 2001; Shah et al., 2001; Craviso et al., 2002; Manni et al., 2002; Zhou et al., 2002; Craviso et al., 2003; Pirozzoli et al., 2003; Shi et al., 2003; Chang et al., 2004; Manni et al., 2004; Bodega et al., 2005; Zhang et al., 2005). Besides, several studies have been linked with EMFs at 50/60 Hz power frequency (Schimmelpfeng and Dertinger, 1997; Aldinucci et al., 2000; Lee and McLeod, 2000; Wei et al., 2000; Golfert et al., 2001; Mangiacasale et al., 2001; Pessina et al., 2001; Craviso et al., 2002; Manni et al., 2002; Zhou et al., 2002; Craviso et al., 2003; Nie and Henderson, 2003; Pirozzoli et al., 2003; Shi et al., 2003; Tokalov and Gutzeit, 2003; Zeng et al., 2003; Manni et al., 2004; Tokalov and Gutzeit, 2004; Bodega et al., 2005; Zhang et al., 2005). Based on extensive search of the literature and preliminary data, we decided the exposure conditions of $2 \mathrm{mT}, 60 \mathrm{~Hz}$, sinusoidal EMF.

For a period up to 14 days, C6 cells were exposed to EMF for $6 \mathrm{~h}$ per day. We examined whether EMF exposure alters proliferation, differentiation, cell cycle distribution and actin distribution of the cells. In our cellular model and under our experimental conditions, EMF either stimulated or inhibited cell proliferation depending on the initial cell seeding density. When the initial seeding density was $10^{3}$ cells per $9.6 \mathrm{~cm}^{2}$ growth areas, EMF accelerated the proliferation of $\mathrm{C} 6$ cells. When the initial seeding density was $10^{4}$ cells per $9.6 \mathrm{~cm}^{2}$ growth areas, however, EMF inhibited cell growth. We hypothesize that these findings were due to insufficient nutrient availability and to the relatively high seeding density of cultures. On the other hand, there was no correlation between EMF exposure and cell differentiation. To support an environment that is permissive for proliferation or differentiation, optimal cell seeding is required. It is the basic idea that there is an inverse relationship between proliferation and differentiation. On the contrary, when the initial seeding density was $10^{4}$ cells per $9.6 \mathrm{~cm}^{2}$ growth areas, the proliferation potential of EMF-treated cells was higher than that of control cells on 14 days of culture. Regardless of the initial cell seeding density, EMF induced the cytoskeletal modification of cells. Exposure to EMF altered the arrangement of actin filaments, by stimulating actin expression at the membrane level.

In conclusion, the observations in this paper support the hypothesis that $2 \mathrm{mT}, 60 \mathrm{~Hz}$, sinusoidal EMF may modify structure and function of C6 glioma cells. Further research is necessary to characterize specifically the cellular responses to EMF under standardized experimental condition. After we better understand and systemize the EMF results on diverse cell lines, EMF stimuli will be beneficially applied to controlling cells. EMF might provide a novel and promising strategy for the regulating cells. 


\section{References}

Aaron, R.K., B.D. Boyan, D.M. Ciombor, Z. Schwartz and B.J. Simon, 2004. Stimulation of growth factor synthesis by electric and electromagnetic fields. Clinical Orthopaedics, 419: 30-37.

Aaron, R.K., S. Wang and D.M. Ciombor, 2002. Upregulation of basal TGF $\beta_{1}$ levels by EMF coincident with chondrogenesis-implications for skeletal repair and tissue engineering. J. Orthopaedic Res., 20: 233-240.

Aldinucci, C., M. Palmi, G. Sgaragli, A. Benocci, A. Meini, F. Pessina and G.P. Pessina, 2000. The effect of pulsed electromagnetic fields on the physiologic behaviour of a human astrocytoma cell line. Biochim. Biophysica Acta, 1499: 101-108.

Anciaux, K., K.V. Dommelen, S. Nicolai, E.V. Mechelen and H. Slegers, 1997. Cyclic AMP-mediated induction of the glial fibrillary acidic protein is independent of protein kinase. A activation in rat C6 glioma. J. Neurosci. Res., 48: 324-333.

Bodega, G., I. Forcada, I. Suarez and B. Fernandez, 2005. Acute and chronic effects of exposure to a 1 -mT magnetic field on the cytoskeleton, stress proteins and proliferation of astroglial cells in culture. Environ. Res., 98: 355-362.

Chang, W.H.S., L.T. Chen and J.S. Sun, 2004. Effect of pulse-burst electromagnetic field stimulation on osteoblast cell activities. Bioelectromagnetics, 25: 457-465.

Craviso, G.L., I. Chatterjee and N.G. Publicover, 2003. Catecholamine release from cultured bovine adrenal medullary chromaffin cells in the presence of $60-\mathrm{Hz}$ magnetic fields. Bioelectrochemistry, 5756: $1-8$.

Craviso, G.L., J. Poss, C. Lanctot, S.S. Lundback, I. Chatterjee and N.G. Publicover, 2002. Intracellular calcium activity in isolated bovine adrenal chromaffin cells in the presence and absence of $60 \mathrm{~Hz}$ magnetic fields. Bioelectromagnetics, 23: 557-567.

Golfert, F., A. Hofer, M. Thummler, H. Bauer and R.H.W. Funk, 2001. Extremely low frequency electromagnetic fields and heat shock can increase microvesicle motility in astrocytes. Bioelectromagnetics, 22: 71-78.

Goodman, R. and M. Blank, 2002. Insights into electromagnetic interaction mechanisms. J. Cellular Physiol., 192: 16-22.

Guerkov, H.H., C.H. Lohmann, Y. Liu, D.D. Dean, B.J. Simon, J.D. Heckman, Z. Schwartz and B.D. Boyan, 2001. Pulsed electromagnetic fields increase growth factor release by nonunion cells. Clin. Orthopaedics Related Res., 384: 265-279.

Landegren, U., 1984. Measurement of cell numbers by means of the endogenous enzyme hexosaminidase. Applications to detection of lymphokines and cell surface antigens. J. Immunol. Methods, 67: 379-388.

Lee, J.H. and K.J. McLeod, 2000. Morphologic responses of osteoblast-like cells in monolayer culture to ELF electromagnetic fields. Bioelectromagnetics, 21: 129-136.

Lohmann, C.H., Z. Schwartz, T. Liu, Z. Li, B.J. Simon, V.L. Sylvia, D.D. Dean, L.F. Bonewald, H.J. Donahue and B.D. Boyan, 2003. Pulsed electromagnetic fields affect phenotype and connexin 43 protein expression in MLO-Y4 osteocyte-like cells and ROS 17/2.8 osteoblast-like cells. J. Orthopaedic Res., 21: 326-334.

Mangiacasale, R., A. Tritarelli, I. Sciamanna, M. Cannone, P. Lavia, M.C. Barberis, R. Lorenzini and E. Cundari, 2001. Normal and cancer-prone human cells respond differently to extremely low frequency magnetic fields. FEBS Lett., 487: 397-403. 
Manni, V., A. Lisi, D. Pozzi, S. Rieti, A. Serafino, L. Giuliani and S. Grimaldi, 2002. Effects of extremely low frequency $(50 \mathrm{~Hz})$ magnetic field on morphological and biochemical properties of human keratinocytes. Bioelectromagnetics, 23: 298-305.

Manni, V., A. Lisi, S. Rieti, A. Serafino, M. Ledda, L. Giuliani, D. Sacco, E. D'Emilia and S. Grimaldi, 2004. Low electromagnetic field $(50 \mathrm{~Hz})$ induces differentiation on primary human oral keratinocytes (HOK). Bioelectromagnetics, 25: 118-126.

Nie, K. and A. Henderson, 2003. MAP kinase activation in cells exposed to a $60 \mathrm{~Hz}$ electromagnetic field. J. Cell. Biochem., 90: 1197-1206.

Pessina, G.P., C. Aldinucci, M. Palmi, G. Sgaragli, A. Benocci, A. Meini and F. Pessina, 2001. Pulsed electromagnetic fields affect the intracellular calcium concentrations in human astrocytoma cells. Bioelectromagnetics, 22: 503-510.

Pirozzoli, M.C., C. Marino, G.A. Lovisolo, C. Laconi, L. Mosiello and A. Negroni, 2003. Effects of $50 \mathrm{~Hz}$ electromagnetic field exposure on apoptosis and differentiation in a neuroblastoma cell line. Bioelectromagnetics, 24: 510-516.

Roymans, D., B. Grobben, P. Claes and H. Slegers, 2001. Protein tyrosine kinase-dependent regulation of adenylate cyclase and phosphatidylinositol 3-kinase activates the expression of glial fibrillary acidic protein upon induction of differentiation in rat C6 glioma. Cell Biol. Intl. 25: 467-474.

Schimmelpfeng, J. and H. Dertinger, 1997. Action of a $50 \mathrm{~Hz}$ magnetic field on proliferation of cells in culture. Bioelectromagnetics, 18: 177-183.

Shah, J.P., P. Midkiff, P.C. Brandt and B.F. Sisken, 2001. Growth and differentiation of PC6 cells: The effects of pulsed electromagnetic fields (PEMF). Bioelectromagnetics, 22: 267-271.

Shi, B., R.R. Isseroff and R. Nuccitelli, 2003. Power line frequency electromagnetic fields do not increase the rate of protein synthesis in human skin fibroblasts as previously reported. Bioelectromagnetics, 24: 465-472.

Tenforde, T.S., 1991. Biological interactions of extremely-low-frequency electric and magnetic fields. Bioelectrochem. Bioenergetics, 25: 1-17.

Tokalov, S.V. and H.O. Gutzeit, 2003. The heat shock-induced cell cycle arrest is attenuated by weak electromagnetic fields. Cell Proliferation, 36: 101-111.

Tokalov, S.V. and H.O. Gutzeit, 2004. Weak electromagnetic fields (50 Hz) elicit a stress response in human cells. Environ. Res., 94: 145-151.

Wei, M., M. Guizzetti, M. Yost and L.G. Costa, 2000. Exposure to $60-\mathrm{Hz}$ magnetic fields and proliferation of human astrocytoma cells in vitro. Toxicol. Applied Pharmacol., 162: 166-176.

Zeng, Q.L., H. Chiang, G.L. Hu, G.G. Mao, Y.T. Fu and D.Q. Lu, 2003. ELF magnetic fields induce internalization of gap junction protein connexin 43 in chinese hamster lung cells. Bioelectromagnetics, 24: 134-138.

Zhang, Y., J. Ding, W. Duan and W. Fan, 2005. Influence of pulsed electromagnetic field with different pulse duty cycles on neurite outgrowth in PC12 rat pheochromocytoma cells. Bioelectromagnetics, 26: 406-411.

Zhou, J., G. Yao, J. Zhang and Z. Chang, 2002. CREB DNA binding activation by a $50-\mathrm{Hz}$ magnetic field in HL60 cells is dependent on extra-and intracellular $\mathrm{Ca}^{2+}$ but not PKA, PKC, ERK, or p38 MAPK. Biochem. Biophy. Res. Comm., 296: 1013-1018. 